\title{
Seeing the entire forest in endocarditis
}

\author{
Vinay Badhwar, MD, Lawrence M. Wei, MD, and J. Scott Rankin, MD
}

\footnotetext{
From the Division of Cardiothoracic Surgery, West Virginia University, Morgantown, WVa.

Disclosures: Dr Rankin is a consultant for Admedus Corp and Chief Medical Officer for BioStable Science and Engineering Inc. All other authors have nothing to disclose with regard to commercial support.

Received for publication May 20, 2016; accepted for publication May 26, 2016; available ahead of print June 18, 2016.

Address for reprints: Vinay Badhwar, MD, Division of Cardiothoracic Surgery, WVU Heart \& Vascular Institute,

West Virginia University, Morgantown, WV (E-mail: vinay.badhwar@wvumedicine.org).

J Thorac Cardiovasc Surg 2016;152:681-2

$0022-5223 / \$ 36.00$

Copyright (C) 2016 by The American Association for Thoracic Surgery

http://dx.doi.org/10.1016/j.jtcvs.2016.05.050
}

In the current issue of the Journal, ${ }^{1}$ Drs Ferraris and Sekela present a timely and impassioned overview of the current epidemic of endocarditis secondary to intravenous drug abuse (IVDA). This story is a sad one, not only for the Appalachian middle class highlighted in this review, but for thousands of patients and their families afflicted at an accelerated rate across the United States. The recent influx of inexpensive options for those tormented by IVDA provides both motive and opportunity for an insidious penetration across the geographic and socioeconomic spectrum.

For the last several years, many of us practicing in urban environments have seen a substantial increase in volume of IVDA-related endocarditis. Once rare, these cases have become so common that they occur several times a week in certain centers. Frequent socioeconomic associations lead to a perception of presumptive regional phenomenon. Although many of us have acknowledged the gravity and depth of the problem, we commonly and naturally revert to addressing this at a patient-level or center-level. Many experienced surgeons realize that it is much more than an inability to "see the forest for the trees" but one of an inability to address the root cause-the epidemic of IVDA.

As the authors ${ }^{1}$ eloquently point out, this problem has become pervasive across all regions and economic strata. The documented up-tick in US death rates is evidence enough for a more aggressive national policy on hard drugs. As physician leaders in our communities, we have an opportunity to address our regional "forest" populations by becoming more active in state and national political discourses. As a consequence of this epidemic, IVDA has now achieved the status of a national crisis. National economic development, more effective local intervention, and legislative efforts to limit narcotic prescriptions are essential.

Perhaps the most direct contribution that we as cardiothoracic surgeons can make is in the form of improved management of valvular endocarditis. It is clear that timely mitral and tricuspid valve repair for endocarditis achieves better early and late outcomes, ${ }^{2,3}$ and techniques for reconstruction of destroyed aortic valves are maturing. ${ }^{4}$

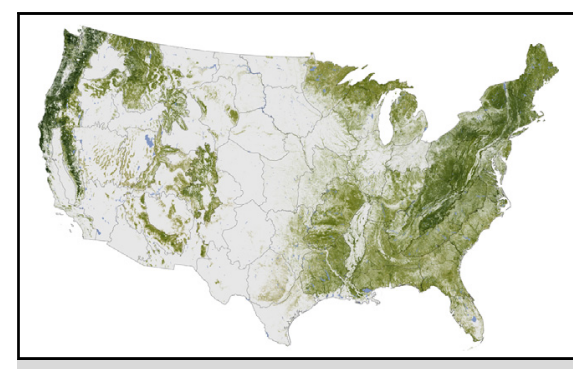

Viewing the US forest organic biomass from NASA's earth observatory. Sometimes we need to step back to see the entire problem.

\section{Central Message}

Viewing the US forest organic biomass from NASA's earth observatory. Sometimes we need to step back to see the entire problem.

See Articles page 677 and 832 .

See Editorial Commentary page 842

Converting predominantly to valve repair instead of replacement whenever possible may have substantive impact.

In the final analysis, the dominant issue is prevention of recidivism, ${ }^{6}$ which produces a major resource strain across several aspects of health care: ethical, social, and financial. In many US hospitals, IVDA-related endocarditis heart teams are being developed. This structure involves surgeons, cardiologists, infectious disease specialists, drug addiction psychiatrists, social workers, medical ethicists, and palliative care specialists. Together, they cultivate pathways of evidence-based management for first-time IVDA-related endocarditis facilitating early diagnosis, and aggressive antimicrobial and surgical therapy. This is followed by engaging regional systems of outpatient drug rehabilitation and social worker home follow-up in an attempt to mitigate medical noncompliance and recidivism.

When a relapse occurs, and patients present with recurrent IVDA-related endocarditis after recent valve operation, it is often the surgeon who is placed in the difficult position to decide when and whether to reoperate, despite a foreknowledge of poor long-term prognosis regardless of a technically excellent result. ${ }^{6}$ Heart teams can provide surgeons much-needed assistance, in the form of standardized protocols and hospital support. Palliative 
care definitely has a role in many of these patients, but it is difficult to tell a 30-year-old habitual IV drug abuser and his or her family, when he or she presents for a third or fourth valve reoperation for IVDA-related endocarditis, that nonsurgical palliation is recommended. All stakeholders need to develop agreed-on algorithms and a system that does not leave the surgeon isolated in these decisions. Indepth discussions of long-term plans and approaches should be completed with the patients before his or her first operation. Despite these efforts, rates of recidivism remain high. If an active national program is not provided to minimize IVDA long-term, the impact to health care will only magnify, and we will miss this opportunity to step back and see the entire forest and not just the trees.

\section{References}

1. Ferraris VA, Sekela ME. Missing the forest for the trees: the world around us and surgical treatment of endocarditis. J Thorac Cardiovasc Surg. 2016;152:677-80.

2. Ruttmann E, Legit C, Poelzl G, Mueller S, Chevchitch O, Cottogni M, et al. Mitral valve repair provides improved outcome over replacement in active infective endocarditis. J Thorac Cardiovasc Surg. 2005;130:765-71.

3. Shang E, Forrest GN, Chizmar T, Chim J, Brown JM, Zhan M, et al. Mitral valve infective endocarditis: benefit of early operation and aggressive use of repair. Ann Thorac Surg. 2009;87:1728-34.

4. Mazzitelli D, Rankin JS, Schreiber C, Lange R. Aortic valve reconstruction for endocarditis using tissue-engineered bovine pericardium. Available at: http://www. ctsnet.org/article/aortic-valve-reconstruction-endocarditis-using-tissue-engineer ed-bovine-pericardium. Accessed March 15, 2016.

5. Gammie JS, O'Brien SM, Griffith BP. Surgical treatment of mitral valve endocarditis in North America. Ann Thorac Surg. 2005;80:2199-204.

6. Kim JB, Ejiofor JI, Yammine M, Ando M, Camuso JM, Youngster I, et al. Surgical outcomes of infective endocarditis in intravenous drug users. J Thorac Cardiovasc Surg. 2016;152:832-41.e1. 